\title{
Beijing proposes law to ban criticism of traditional Chinese medicine
}

\author{
Owen Dyer
}

Montreal

A law proposed by the Beijing municipality could criminalise statements critical of traditional Chinese medicine, at a time when China's government is claiming, without clear evidence, that many traditional medicines are effective against covid- 19 .

The draft law, which is open for public comment until 28 June, would ban making exaggerated claims for traditional medicines' efficacy but also outlaws "denigrating or defaming traditional Chinese medicine." That could place critics of traditional Chinese medicine at odds with a government that officially promotes its use and recommends six traditional recipes for the prevention or treatment of covid-19.

The six medicines, each a mixture of several herbs, are Jinhua Qinggan granules, Lianhua Qingwen capsules, Xuebijing injection, lung cleansing, and detoxifying decoction, Huashi Baidu formula, and Xuanfei Baidu granules. They have been recommended by China's state media, which provides a few details from studies of their efficacy against covid-19.

The studies have not been published elsewhere, although Huang Luqi, a practitioner of traditional Chinese medicine and head of the China Academy of Chinese Medical Sciences in Beijing, told Nature that they would be published soon. He also claimed to have since led studies of three other traditional medicines, which he said all proved safe and effective.

China's government has said that 74000 covid-19 patients received traditional medicines, which proved "90\% effective."

Critics say the studies were not double blinded and had other methodological flaws. Chinese doctors are strongly encouraged to give traditional Chinese medicines alongside modern drugs to almost all patients, making it difficult to examine their effect.

Some of the six medicines recommended for covid-19 contain the pseudoephedrine bearing herb Ephedra sinica, which was banned from weight loss and energy supplements by the US Food and Drug Administration, and by some European countries, after a string of deaths in the 1990s. Traditional Chinese medicines have also been criticised for links with the trade in wild animals.

The Chinese government has forcefully backed the industry, passing a first law to foster its development in 2016. President $\mathrm{Xi}$ Jinping is a keen supporter, seeing traditional Chinese medicine as a pillar of the rural economy and a source of national pride. With roughly 4000 traditional medicine hospitals and 42000 clinics seeing more patients every year, China's government estimates the industry to be worth about $\$ 400 \mathrm{bn}$ annually.

China has included its traditional medicines in covid-19 aid packages to other countries, alongside more conventional drugs and equipment.

The proposed law attracted scorn from commenters on Weibo, China's equivalent to Twitter. "Is there a thing called defaming modern medicine, physics, chemistry and astronomy?" asked one user. "Using legal means to intervene in science-isn't this like the Catholic Church cracking down on heliocentrism?"

"It will be a luxury to speak the truth in the future," complained another comment.

6 effective TCM recipes for covid-19. China Daily. 24 Mar 2020. https://covid-19.chinadaily. com.cn/a/202003/24/WS5e795bb6a3101282172816c2.html.

This article is made freely available for use in accordance with BMJ's website terms and conditions for the duration of the covid-19 pandemic or until otherwise determined by BMJ. You may use, download and print the article for any lawful, non-commercial purpose (including text and data mining) provided that all copyright notices and trade marks are retained.

https://bmj.com/coronavirus/usage 